\title{
Percepção de alunos de engenharia ambiental sobre o tema das mudanças climáticas e sua área de atuação profissional
}

\author{
Karina da Costa Sousa \\ Mestranda em Ensino e História de Ciências da Terra \\ (PEHCT) , Universidade Estadual de Campinas, SP \\ karinasousa@ige.unicamp.br \\ Denise de La Corte Bacci \\ Instituto de Geociências, Universidade de \\ São Paulo, SP \\ bacci@usp.br
}

\begin{abstract}
Perception Of EnVironmental Engineering Students About The Climate Change AND Their PROFESSIONAL AREA - The present work is devoted to investigate how students of an undergraduate course on Environmental Engineering of the University of Uberaba, situated in Uberaba, MG, Brazil, understand the relationship between Climate change and their professional area, using a questionnaire and Discursive Textual Analysis. This work is part of a research which is being developed at the Graduate Program in Teaching and History of Earth Sciences of the Institute of Geosciences of the University of Campinas. Students' answers have been analyzed and results show that students recognize the relationship between the theme and their future professional activity, evidencing two major arguments: firstly which considers that the subject must be discussed in work projects, and another which indicates environmental engineers' competence in mitigating environmental impacts related to climate change. Citation: Sousa K.C., Bacci D.L.C. 2014. Percepção dos alunos de engenharia ambiental sobre o tema das mudanças climáticas e sua área de atuação profissional. Terræ Didatica, 10(3):394-406. http://www.ige.unicamp.br/terraedidatica/.
\end{abstract}

KEYWORDS: Environmental Engineering; climate change; professional activity, Discursive Textual Analysis.

RESUMO O trabalho apresenta os resultados preliminares de pesquisa em andamento sobre a percepção dos alunos do curso de Engenharia Ambiental da Universidade de Uberaba, localizada em Uberaba, MG, sobre as relações entre a temática das Mudanças Climáticas e sua área profissional, por meio da aplicação de questionário estruturado e da análise textual discursiva. A pesquisa está sendo realizada no âmbito do Programa de Pós-Graduação em Ensino e História de Ciências da Terra, do Instituto de Geociências da Universidade Estadual de Campinas, e procura investigar a temática em três cursos de engenharia ambiental e as relações com a atuação profissional do engenheiro. Os resultados obtidos até o momento indicam que os alunos percebem a importância do tema para sua futura atuação profissional, evidenciando duas linhas de argumentação: a primeira que considera que o tema deva ser abordado em projetos de trabalho e outra que indica a competência do engenheiro ambiental para mitigar impactos ambientais relacionados às mudanças climáticas.

PALAVRAS-CHAVE: Engenharia Ambiental; mudanças climáticas; atuação profissional, Análise Textual Discursiva. 


\section{Introdução}

A problemática ambiental, foco de diversos estudos e discussões atuais, está cada vez mais relacionada ao tema das mudanças climáticas. Tal assunto é uma preocupação de vulto na atualidade, uma vez que tem influenciado várias esferas de atividades e pensamento humanos, especialmente a esfera socioeconômica, em caráter global. É também objeto de controvérsia no meio científico, no que diz respeito aos fatores que condicionam sua ocorrência. Segundo os relatórios do Intergovernmental Panel on Climate Change - IPCC, as atividades antrópicas funcionam como agente transformador do ambiente terrestre em escala global. Em contrapartida, cientistas denominados céticos (Durkin 2007, Molion 2008, Suguio 2010), defendem que não é possível que a dinâmica climática global seja influenciada por atividades antrópicas, especialmente a emissão dos chamados gases de efeito estufa (GEE), que seriam mesmo insignificantes se comparadas a outros fatores naturais ao longo do Tempo Geológico. O posicionamento político do Brasil frente a esta discussão se situa na direção de concordância com o IPCC. O país é signatário da Convenção-Quadro das Nações Unidas sobre a Mudança do Clima (UNFCCC - United Nations Framework Convention on Climate Change), um tratado internacional resultante da Conferência das Nações Unidas para o Meio Ambiente e o Desenvolvimento realizada na cidade do Rio de Janeiro, no ano de 1992 (também conhecida como ECO-92), que definiu uma série de compromissos dos países signatários no sentido de se desenvolver ações de mitigação e adaptação à mudança climática global. Uma das medidas adotadas pelo Brasil foi a instituição da Política Nacional sobre Mudança do Clima, lei no 12.187, de 29 de dezembro de 2009, que estabelece metas oficiais de redução da emissão de gases de efeito estufa, e que fundamentou o desenvolvimento de políticas sobre mudança climática também nas esferas estadual e municipal (como é o caso do município de São Paulo). No artigo 12 está disposto que o país adotará ações com vistas a reduzir entre $36,1 \%$ e $38,9 \%$ suas emissões projetadas até 2020 (Brasil 2009). De acordo com o Decreto n. ${ }^{\circ} 7.390$, de 09 de dezembro de 2010, o total de emissões estimado para o ano de 2020 equivale a 3.236 milhões tonCO $\mathrm{CO}^{2}$ eq. Assim, a redução absoluta correspondente ao que dispõe a Política Nacional sobre Mudança do Clima ficou estabelecida entre 1.168 milhões de tonCO ${ }^{2}$ eq e 1.259 milhões de tonCO ${ }^{2}$ eq.

Essa temática é interdisciplinar e está presente em vários cursos de formação das mais diversas áreas profissionais, pois configura-se na interface ambiente e sociedade. E, nesse contexto de preocupação acerca das relações entre ambiente e sociedade, de forma geral, apresenta-se a criação dos cursos de Engenharia Ambiental no Brasil.

O primeiro curso de engenharia ambiental brasileiro entrou em funcionamento em 1992, na Universidade Federal do Tocantins. O histórico de surgimento do curso remonta às atividades exercidas pelos engenheiros sanitaristas nas últimas décadas do século passado. À época da vigência do Planasa (Plano Nacional de Saneamento do Brasil), instalado em 1968 de modo experimental e em 1971 de maneira formal pelo Banco Nacional da Habitação (Monteiro 1993), a instituição eleita para exercer sua administração foi a ABES - Associação Brasileira de Engenharia Sanitária e Ambiental, que congrega profissionais do saneamento básico. A partir da perda de espaço da Engenharia Sanitária, que era mais focada nos recursos hídricos e com uma forte ligação com a Engenharia Civil, conforme explica a publicação mensal Conselho em Revista, do Conselho Regional de Engenharia, Arquitetura e Agronomia do Rio Grande do Sul (CREA-RS), datada de maio de 2007, criou-se o curso de Engenharia Ambiental. Além disso, outro fator que determinou a criação do curso, ainda segundo o texto da publicação mencionada, foi a intensificação da preocupação ambiental, observada a partir da década de 1980, que apontou a necessidade de se criar outra disciplina, mais multidisciplinar que a Engenharia Sanitária. No que concerne à função desta nova modalidade da engenharia:

"Ela (a engenharia ambiental) busca conciliar de maneira harmoniosa desenvolvimento e meio ambiente, visando o levantamento e a redução de possíveis danos ocasionados pelo ser humano através de sua influência na natureza. Para isso, o profissional tem uma formação multidisciplinar, com conhecimentos de Química, Física e Matemática, além de áreas específicas como hidrologia, climatologia, saúde ambiental, tratamento de afluentes, tratamento de resíduos, avaliação de impacto ambiental, gestão ambiental, planejamento, entre outros. O engenheiro ambiental atua de maneira conjunta com profissionais de diversas áreas, 
analisando o impacto na natureza de processos e obras, no intuito de evitar ou minimizar danos." (CREA-RS 2007)

Existem no Brasil atualmente 123 cursos cadastrados no MEC, com a denominação de Engenharia Ambiental, outros 145 cursos denominados Engenharia Ambiental e Sanitária, além deseis cursos com a denominação de Engenharia Ambiental e Energias Renováveis e dois chamados Engenharia Ambiental e Urbana. Destes, quatro cursos são oferecidos à distância e os outros 272 são presenciais. Tais dados estão disponíveis para consulta no sistema e-MEC, do Ministério da Educação, acessível no link: http://emec.mec.gov.br/. A legislação que regulamenta a profissão é representada principalmente pela Portaria n. ${ }^{\circ} 1.693$, de 5 de dezembro de 1994, que criou a área de Engenharia Ambiental, além da Resolução n. ${ }^{\circ} 447$, de 22 de setembro de 2000, que dispõe sobre o registro profissional do engenheiro ambiental e discrimina suas atividades profissionais. Outras normas de interesse são a Resolução n. ${ }^{\circ}$ 218, de 29 de junho de 1973, que discrimina as atividades das diferentes modalidades profissionais da Engenharia, da Arquitetura e da Agronomia; a Resolução n. ${ }^{\circ}$ 48, de 27 de abril de 1976, que fixa os mínimos de conteúdo e duração do currículo do curso de graduação em Engenharia e define suas áreas de habilitação, e a Resolução do Conselho Nacional de Educação/Câmara de Educação Superior n. ${ }^{\circ} 11$, de 11 de março de 2002, que institui as diretrizes curriculares nacionais do curso de graduação em engenharia. No que se refere ao mercado de trabalho e à atuação do engenheiro ambiental:

"O engenheiro ambiental, por ter conhecimento detalhado dos processos químicos, físicos e biológicos e possuir conhecimentos capazes de minimizar os impactos na natureza, tem a possibilidade de atuar nas mais diversas áreas. Como exemplos estão as áreas de gestão ambiental e tecnologia de órgãos públicos, indústrias, consultorias e empresas privadas. Algumas possibilidades estão em centros de pesquisa, organizações não-governamentais (ONGs), agências reguladoras de água, energia elétrica e vigilância sanitária, universidades e indústrias das mais variadas atividades, empresas de consultoria privada e instituições encarregadas da definição de políticas públicas ambientais. (...)As áreas em que há melhores oportunidades de emprego são as mais industrializadas, fundamentalmente as Regiões Sul e Sudeste.” (CREA-RS 2007).

Tendo em vista o contexto apresentado, o presente estudo objetivou investigar a percepção de alunos do curso de Engenharia Ambiental da Universidade de Uberaba, localizada na cidade de Uberaba/MG, quanto às relações de sua futura atuação profissional e a temática das mudanças climáticas, considerando a proposta deste curso e a relevância do tema para a área ambiental. A grade curricular do curso foi analisada a partir das ementas das disciplinas, identificando-se aquelas que contemplam ou tangenciam temas relacionados às mudanças climáticas. A partir deste critério, foram selecionadas as disciplinas e aplicados questionários aos alunos nelas matriculados.

A cidade de Uberaba localiza-se na região do Triângulo Mineiro. Segundo dados do sistema IBGE-Cidades@ (disponíveis no linkhttp://www. cidades.ibge.gov.br), a cidade possuía, no ano de 2010, uma população de 295.988 habitantes, com a estimativa de 318.813 habitantes para o ano de 2014. Compreende uma área 4.523,957 km², (IBGE 2010), sendo aproximadamente $256 \mathrm{~km}^{2} \mathrm{de}$ área urbana, e o restante abrangendo a área rural. No que se refere ao setor econômico, o sistema IBGE-Cidades@ informa que o setor de serviços é responsável por aproximadamente $49,78 \%$ do valor adicionado bruto do Produto Interno Bruto (PIB) do município, a indústria por $28,18 \%$ e a agropecuária por 7,18\%. Embora a agropecuária apresente menor contribuição para o PIB municipal, se comparado ao setor industrial e ao de serviços, a atividade é tradicional no município, havendo diversas indústrias destinadas a produzir insumos e a beneficiar produtos agropecuários.

Das instituições de ensino superior presentes na cidade, três oferecem o curso de Engenharia Ambiental: a Universidade de Uberaba (UNIUBE), a Faculdade de Talentos Humanos (Facthus), ambas instituições particulares, e a Universidade Federal do Triângulo Mineiro (UFTM). O primeiro curso de Engenharia Ambiental ofertado na cidade foi o da Faculdade de Talentos Humanos. Seu início foi autorizado pelo Ministério da Educação através da Portaria Ministerial n. ${ }^{\circ}$ 623, de 01 de março de 2005, e o nome do curso, conforme consta do relatório do sistema e-MEC é Engenharia Ambiental e Sanitária. O curso de graduação em Engenharia Ambiental da Univer- 
sidade de Uberaba (UNIUBE) teve início no ano de 2006. A UNIUBE possui dois cursos de Engenharia Ambiental cadastrados no sistema e-MEC: o curso do campus de Uberaba e o curso do campus de Uberlândia-MG; e ainda o curso a distância de Engenharia Sanitária e Ambiental. A análise proposta neste estudo foi feita para o curso presencial do campus de Uberaba. Este curso é ofertado nos períodos noturno e integral, e o tempo mínimo de integralização curricular é de 10 semestres. O atual Conceito de Curso (CC), obtido na última avaliação do INEP (Instituto Nacional de Estudos e Pesquisas Educacionais Anísio Teixeira) é 4, de acordo com o sistema e-MEC. O curso de Engenharia Ambiental da Universidade Federal do Triângulo Mineiro - UFTM, é o mais recente da cidade - tendo iniciado no ano de 2010, e ainda não possui turmas diplomadas.

\section{Método de investigação}

A fim de se alcançar o objetivo proposto por este estudo, aplicou-se um questionário estruturado aos alunos do curso de graduação em Engenharia Ambiental da Universidade de Uberaba, para uma disciplina específica. O questionário objetivou investigar as concepções dos graduandos quanto ao tema das mudanças climáticas. $\mathrm{O}$ contato com a instituição foi feito através de correio eletrônico. Inicialmente, foi solicitada ao professor coordenador do curso a autorização para desenvolvimento do trabalho. Ao autorizar a realização da pesquisa na instituição, o coordenador forneceu o Projeto Pedagógico do Curso de Graduação em Engenharia Ambiental e Sanitária Modalidade à Distância referenciado doravante como PPC (projeto pedagógico do curso), explicando que se trata do mesmo PPC do curso presencial do campus de Uberaba. A partir deste documento, realizou-se uma leitura inicial do ementário do curso e um questionário qualitativo de três questões foi elaborado e aplicado aos alunos da disciplina de Climatologia. As questões inquiriam sobre as concepções dos alunos a respeito do tema das mudanças climáticas, sobre sua relação com a futura atuação profissional e sobre a contribuição das Geociências para a compreensão do tema. Numa primeira etapa, os questionários foram enviados aos alunos do curso por correio eletrônico, mas, poucas respostas foram obtidas (sete em trinta e cinco alunos responderam). Devido a esta baixa participação, uma segunda rodada foi aplicada, neste caso os alunos da disciplina de Climatologia e de outras disciplinas, selecionadas a partir das ementas e das relações com o tema das mudanças climáticas. O contato inicial foi com os professores responsáveis, solicitando-se autorização para aplicar o questionário, desta vez presencial. O tempo estimado de aplicação dos questionários foi de cerca de 35 minutos. Obteve-se assim uma amostragem de 42 estudantes ao final do segundo semestre de 2013. A metodologia que guiou a análise dos resultados obtidos foi a Análise Textual Discursiva.

\section{Coleta de dados: a seleção das disciplinas e a elaboração dos questionários}

As mudanças climáticas relacionam-se com uma grande quantidade de conceitos abordados no curso de Engenharia Ambiental. Por meio da análise das ementas identificamos quais disciplinas tratam do tema de forma direta ou relacionam-se a ele de forma indireta. As pesquisas indicaram essas relações com as seguintes áreas do conhecimento: da Análise de Riscos, do Direito Ambiental, da Gestão de Recursos Energéticos, da Valoração e Contabilidade Ambiental, da Saúde Pública e do Planejamento Urbano, campos que compõem o currículo do curso investigado. A propósito, Martins et al. (2010) discorreram sobre mudanças climáticas e vulnerabilidade na agricultura, tratando conceitos de risco e de vulnerabilidade do setor agrícola, da percepção deste setor sobre as mudanças do clima e de sua capacidade de adaptação, apontando desafios para o desenvolvimento de estratégias de mitigação e adaptação do setor ao processo de mudança. Ojima e Marandola Jr. (2010) também discutiram riscos e vulnerabilidade do ambiente às Mudanças Climáticas, mas trataram especificamente das áreas urbanas e da necessidade de se estabelecer indicadores eficazes da vulnerabilidade e de se desenvolver políticas públicas urbanas de adaptação aos impactos decorrentes da mudança do clima, aspectos que devem ser considerados no processo de planejamento urbano. Rodrigues (2012) analisou as regulamentações ambientais internacionais e o seu reflexo nas legislações federais, estaduais (São Paulo) e municipais (São Paulo), contribuindo para a discussão sobre a imposição internacional de alcance do desenvolvimento sustentável a partir da mitigação das mudanças climáticas e as consequências disto para o desenvolvimento industrial, econômico e social da nação signatá- 
ria, em um trabalho que aborda questões relativas ao Direito Ambiental. No trabalho de Silva et al. (2010), desenvolvido por pesquisadores do Instituto de Comunicação e Informação Científica e Tecnológica em Saúde e do Instituto Leônidas e Maria Deane, ambos da Fundação Oswaldo Cruz (ICICT/Fiocruz e CPqLMD/Fiocruz) denominado "Vulnerabilidade e efeitos das mudanças climáticas na saúde pública em Manaus”, foram consideradas as principais ameaças das alterações climáticas à cidade de Manaus: o regime hidrológico e as doenças relacionadas à água. Segundo os autores, a influência dos rios e igarapés da região favorece a transmissão de doenças de veiculação hídrica. Assim, em caso de ocorrência de enchentes, o risco de incidência aguda dessas doenças aumenta, e, por outro lado, nos episódios de seca o sistema ecológico é desestabilizado e a locomoção de pessoas e transporte de alimentos é inviabilizado. Lucena et al. (2009), embora orientando cautela na interpretação dos resultados obtidos em seu estudo, devido às grandes incertezas sobre os impactos da concentração dos gases de efeito estufa (GEE) na atmosfera, analisaram os impactos da mudança climática no sistema hidrelétrico brasileiro, utilizando dois cenários de emissão previstos, propostos pelo Relatório Especial do Painel Intergovernamental de Mudanças Climáticas sobre Cenários de Emissões (IPCC 2000): o cenário A2, que resumidamente pode ser caracterizado como um cenário pessimista, de alta emissão de GEE, e o cenário B2, otimista e de baixa emissão. Seus resultados, que apontam, segundo os próprios autores, tendências e direções e dependem intrinsecamente das projeções climáticas adotadas, mostraram que a energia firme do sistema de geração hidrelétrico do país cai em $31 \%$ e 29\% nos cenários A2 e B2, respectivamente, não havendo, contudo, nenhum impacto agregado relevante sobre a média de eletricidade gerada, embora impactos regionais significativos tenham sido projetados. Os autores ainda lembram que a mudança climática global também pode afetar o fornecimento (de energia) com origem em outras fontes de energia renováveis (como energia eólica e biocombustíveis líquidos) e não renováveis (como geração termelétrica e a gás) (Schaeffer et al. 2008 apud Lucena et al. 2009). Os exemplos mostrados foram apresentados de forma resumida, mas ilustram as diversas possibilidades de realização de pesquisas e estudos sobre Mudanças Climáticas no âmbito do curso de Engenharia Ambiental.
Algumas disciplinas guardam, no entanto, relações diretas com o tema, como é o caso das disciplinas Climatologia, Geologia Ambiental, Poluição Atmosférica, Biologia, Ecologia, Química Ambiental, Geologia Geral, Hidrologia, Recursos Hídricos e Educação Ambiental. Em seu conjunto, elas fornecem conhecimentos fundamentais para a formação do Engenheiro Ambiental, tanto dos conceitos sobre ambiente como das relações sociedade e natureza. No caso da Química Ambiental, por exemplo, os autores Ometto e Martinelli (2008) explicam:

"As trocas entre a superfície terrestre e a atmosfera
são componentes cruciais nos ciclos de pratica-
mente todos os elementos geoquimicamente ati-
vos, incluindo a água, carbono, nitrogênio, meta-
no, compostos orgânicos voláteis, entre outros. À
medida que essas trocas ocorrem, as concentrações
desses elementos na atmosfera são alteradas, tanto
espacialmente quanto temporalmente, culminando
com uma situação transiente tanto em magnitude
quanto na distribuição de suas fontes e sorvedou-
ros na superfície terrestre. Podemos, dessa forma,
associar os processos que determinam mudanças
nas condições climáticas às possíveis alterações na
composição dos biomas e, onsequentemente, na
cilagem dos elementos a eles associados." (Ometto
e Martinelli 2008, p.30)

Outro exemplo é a Geologia:

A geologia está em uma posição chave ao se discutir sobre as mudanças climáticas. (...) porque a geologia é a ciência que pesquisa, entre outros temas, o passado da Terra. (...) Os acontecimentos do nosso planeta foram gravados em camadas de rochas sedimentares, que são lidas e interpretadas pelos geólogos. Os processos e as mudanças geológicas relacionadas cobrem milhares, milhões ou até bilhões de anos. Por isto, é necessário se considerar uma perspectiva de tempo mais ampla quando pesquisamos diferentes ciclos, p.ex. em relação às mudanças climáticas. (Eerola 2003)

O mesmo autor ainda cita que: “(...) contar sobre as mudanças climáticas do passado ao público e aos administradores pode trazer novas perspectivas ao debate atual” (Eerola 2003). Quanto à problemática atual dos recursos hídricos, relacionada à sua disponibilidade e gestão, os autores Marengo et al. (2011) ressaltam que o impacto das 
mudanças climáticas sobre os recursos hídricos não pode ser tratado isoladamente dos usos atuais do recurso, mas, certamente, essas mudanças poderão exacerbar e acentuar todos os problemas antes assinalados (os autores citaram problemas como intensa urbanização, aumento da demanda por água, infraestrutura precária, estresse e escassez do recurso, dentre outros).

A Climatologia discute este tema ao tratar do sistema climático e de suas variações. Marengo (2009) argumenta que "como resultado das mudanças climáticas provocadas pelo homem, a frequência dos eventos climáticos extremos aumentou, tanto em termos de quantidade quanto de intensidade. Isso passou a ser observado de modo mais nítido a partir da segunda metade do século 20".

Algumas das disciplinas do curso de Engenharia Ambiental aqui discutidas são essenciais na formação profissional do engenheiro ambiental para o entendimento das Mudanças Climáticas: tais como a Geologia, a Climatologia, a Hidrologia, a Poluição Ambiental, a Ecologia Geral e Aplicada e Recursos Naturais, além da Biologia, disposta como matéria de formação básica da área. Estas disposições são dadas pela Portaria n. ${ }^{\circ}$ 1.693/94, que cria a área de Engenharia Ambiental.

Diante da pertinência do tema das mudanças climáticas no campo de atuação dos egressos do curso, foram selecionadas e investigadas as disciplinas listadas na tabela 1 .

Selecionadas as disciplinas, elaborou-se novo questionário com cinco perguntas dissertativas.
As questões buscaram investigar quatro aspectos principais: a abordagem do tema nas disciplinas; as concepções dos alunos sobre o tema; a percepção a respeito das relações entre o tema e sua futura atuação profissional e a percepção a respeito da contribuição do conhecimento geocientífico para sua formação. A análise dos questionários aqui apresentada corresponde às respostas à pergunta relativa à percepção do tema em relação à atuação profissional. Cada resposta obtida foi identificada com um código composto por letras, números e símbolo. A primeira letra indica a instituição ("U" para Uniube). A(s) próxima(s) letra(s) indica(m) a disciplina ("C" para Climatologia; "M" para Monitoramento Ambiental e "Et" para Ecotoxicologia). O número seguido de ponto final indica a numeração da pergunta (a questão referente à atuação profissional é a quinta do questionário); e os números que aparecem após o ponto final indicam a numeração dada a cada questionário respondido.

\section{Análise de dados: a Análise Textual Discursiva}

A metodologia utilizada para análise dos resultados obtidos compreende a Análise Textual Discursiva - ATD, que pode ser considerada como uma análise textual qualitativa, voltada à produção de compreensões aprofundadas e criativas (Moraes e Galiazzi 2007) sobre o fenômeno em estudo. A análise se baseou principalmente no trabalho de Moraes e Galiazzi (2007), Moraes (2003), além do estudo de Melo (2012), em que a autora também

Tabela 1. Disciplinas selecionadas nas três instituições para aplicação do questionário

\begin{tabular}{|c|c|c|c|c|}
\hline \multirow{7}{*}{ 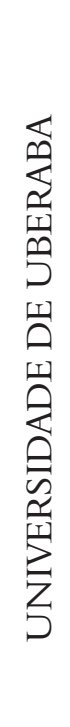 } & Disciplina & $\begin{array}{l}\text { Período } \\
\text { de oferta }\end{array}$ & Situação & $\begin{array}{l}\text { Quantidade } \\
\text { de } \\
\text { respondentes }\end{array}$ \\
\hline & Climatologia & $4^{\circ}$ & Questionários aplicados & 23 \\
\hline & $\begin{array}{c}\text { Controle da poluição ambiental I } \\
\text { (Ecotoxicologia) }\end{array}$ & $6^{\mathrm{O}}$ & Questionários aplicados & 5 \\
\hline & $\begin{array}{c}\text { Controle da poluição ambiental } \\
\text { III (Poluição Sonora e } \\
\text { Atmosférica) } \\
\end{array}$ & $8^{\circ}$ & $\begin{array}{l}\text { Não ofertada no } \\
\text { semestre }\end{array}$ & - \\
\hline & $\begin{array}{c}\text { Saúde pública e educação } \\
\text { ambiental }\end{array}$ & $9^{\circ}$ & $\begin{array}{c}\text { Não ofertada no } \\
\text { semestre }\end{array}$ & - \\
\hline & $\begin{array}{l}\text { Controle da poluição ambiental } \\
\text { IV (Monitoramento ambiental) }\end{array}$ & $9^{\circ}$ & Questionários aplicados & 14 \\
\hline & $\begin{array}{c}\text { Preservação, conservação e } \\
\text { recuperação de recursos naturais } \\
\text { IV }\end{array}$ & $9^{\circ}$ & $\begin{array}{c}\text { Não ofertada no } \\
\text { semestre }\end{array}$ & - \\
\hline
\end{tabular}

Total: 
Tabela 2. Categorias estabelecidas a partir da percepção dos respondentes sobre as relações entre o tema das mudanças climáticas e sua área de atuação profissional

\begin{tabular}{|c|c|c|c|c|c|}
\hline \multirow{2}{*}{$\begin{array}{l}\text { Nome da } \\
\text { categoria }\end{array}$} & Climatologia & $\begin{array}{c}\text { Monitoramento } \\
\text { ambiental }\end{array}$ & Ecotoxicologia & \multicolumn{2}{|c|}{ Total Geral } \\
\hline & Quantidade de & alunos que se refe & iram à categoria & Absoluto & Relativo* \\
\hline $\begin{array}{c}\text { A - Aplicação do } \\
\text { conhecimento } \\
\text { sobre o clima em } \\
\text { projetos }\end{array}$ & 12 & 4 & 1 & 17 & $40,48 \%$ \\
\hline $\begin{array}{l}\text { B - Mitigação } \\
\text { de impactos } \\
\text { ambientais } \\
\text { relacionados } \\
\text { às mudanças } \\
\text { climáticas }\end{array}$ & 8 & 6 & & 14 & $33,33 \%$ \\
\hline
\end{tabular}

utiliza a metodologia para analisar questionários qualitativos aplicados a estudantes universitários.

Iniciou-se pela leitura denominada flutuante (Franco 2003), considerada uma pré-análise neste caso, que busca coletar informações do "corpus" da análise, que, segundo Bardin (1977 apud Melo 2012), é o conjunto de documentos a serem submetidos ao processo analítico. No caso deste trabalho, o "corpus" é constituído pelos questionários aplicados aos estudantes. Após isso, parte-se para as etapas da ATD, que, segundo Moraes e Galiazzi (2006, 2007), são a unitarização, a categorização e a comunicação. Os autores explicam que a primeira etapa consiste na desconstrução do texto. Examina-se os materiais em seus detalhes, a fim de se identificar unidades constituintes, denominadas unidades de análise, definidas em função dos propósitos da pesquisa. Cada unidade constituirá um elemento de significado do "corpus", podendo o texto ser tão desmembrado quanto forem os sentidos possíveis de serem construídos a partir da análise. A segunda etapa, a categorização, é um processo de constante comparação entre as unidades definidas para reunir elementos semelhantes, definir e nomear categorias. Pode-se chegar às categorias a partir de métodos dedutivos ou indutivos. No caso deste trabalho, o caminho percorrido foi o indutivo, através do qual as categorias emergiram. Definidas as categorias, inicia-se um momento de explicitação dos argumentos parciais, buscando um argumento aglutinador do todo, segundo Melo (2012). A impregnação pelos dados, possibilitada pelas duas etapas anteriores, provoca uma compreensão renovada do todo. Esta é a última etapa da análise. "O metatexto resultante deste processo representa um esforço em explicar a compreensão que se apresenta como produto de uma nova combinação dos elementos construídos ao longo dos passos anteriores" (Moraes e Galiazzi 2007, p. 191). O metatexto é o produto final da ATD e, de acordo com Melo (2012, p.10), é a expressão das principais ideias emergentes das análises e dos argumentos construídos pelo pesquisador, não constituindo, assim, uma expressão objetiva dos conteúdos de análise, mas as construções e interpretações pessoais do pesquisador. A seguir, será apresentada a discussão sobre os resultados obtidos, ou, colocando em termos da ATD, serão apresentados os metatextos resultantes da impregnação pelos dados analisados.

\section{Resultados e Discussão}

A questão que investigou a percepção dos estudantes a respeito da relação entre sua futura atuação profissional e o tema das mudanças climáticas foi a seguinte: "Na sua opinião, o tema mudanças climáticas se relaciona de alguma forma com as atividades que você poderá desenvolver como engenheiro ambiental? Se sim, de que forma?" Os questionários foram aplicados aos alunos das disciplinas de Climatologia, Controle da poluição ambiental I (Ecotoxicologia) e Controle da poluição ambiental IV (Monitoramento ambiental).

De acordo com a ATD, as respostas dos alunos que participaram deste estudo foram analisadas e destacadas suas principais ideias - "unitarizando" os sentidos expressos em suas respostas. A partir destas ideias "unitarizadas", as categorias emergiram, uma vez que não foram definidas categorias $a$ priori (Moraes e Galiazzi 2007). A tabela 2 mostra as categorias emergentes do procedimento analítico.

Conforme pode ser observado na Tabela 2, do total de respostas dos alunos da disciplina 
Controle da poluição ambiental I (Ecotoxicologia), apenas uma foi categorizada. Isto se deu porque, dos cinco respondentes, dois afirmaram não ter conhecimento sobre o assunto; um não respondeu a questão, e outro disse não considerar relações entre o tema e seu campo de atuação profissional. A resposta categorizada foi semelhante a respostas obtidas nas outras disciplinas, declarando o aluno que o tema "pode ser uma questão relevante na tomada de decisão sobre algum projeto a ser iniciado" (UET5.02). Deste modo, infere-se que o tema das mudanças climáticas pode não estar sendo tratado em sala de aula, embora a ementa desta disciplina relacione tópicos tais como "estudo dos processos químicos naturais que acontecem na atmosfera" e "alterações dos processos naturais provocadas por poluentes", que abarcam discussões a esse respeito. De fato, outra pergunta presente no questionário inquire se o tema é abordado pelo professor, ao que apenas um aluno responde afirmativamente, explicando que "ele (o professor) abordou essa questão em diferentes aspectos no semestre inteiro" (UET5.05).

Quanto às respostas obtidas nas turmas de Climatologia e Controle da poluição ambiental IV (Monitoramento ambiental), é possível estabelecer em ambas as turmas, duas linhas de argumentação, as quais permitiram a emergência das categorias A e B, mostradas na Tabela 2. Porém, as tendências foram inversas nestas turmas, como mostram os dados relativos à quantidade de alunos que se referiram a cada categoria no âmbito destas disciplinas. A maior parte dos alunos da disciplina de Climatologia se referiu à categoria $\mathrm{A}$, enquanto que as respostas dos alunos de Monitoramento Ambiental focaram a mitigação de impactos relacionados às mudanças no clima, configurando a categoria $\mathrm{B}$.

Enfatizar-se-á, a seguir, as principais concepções dos alunos, de acordo com cada categoria identificada, exemplificando por meio da transcrição das respostas e comparando-as com os dados do projeto pedagógico, bem como dados disponíveis na literatura, a fim de fundamentar a análise.

\section{Categoria A: Aplicação do conhecimento sobre 0 clima em projetos}

Dos 42 respondentes, 17 consideram que os conhecimentos a respeito do clima e suas mudanças devem ser considerados e aplicados nos projetos que desenvolverão como engenheiros ambien- tais. As respostas transcritas abaixo exemplificam a argumentação das respostas pertencentes a esta categoria.

"Este tema é passível para alterações em várias áreas de atuação da Engenharia Ambiental, trabalhos de recuperação de áreas degradadas, sistemas de plantio, determinação de estudos de impacto ambiental e etc.". (UC5.05)

"Sim, as mudanças climáticas não influenciarão apenas nas atividades de um engenheiro ambiental, mas em várias áreas, pois o clima é fato determinante de várias atividades, como plantio, planejamento de construções, e etc.". (UC5.16)

"Sim. Devemos ter o conhecimento das mudanças climáticas, de climatologia em geral, porque para um engenheiro ambiental, tanto na agricultura como na construção, interfere no seu trabalho". (UC5.19)

"Sim. As mudanças climáticas que vem ocorrendo atualmente trazem algumas situações inesperadas, como por exemplo, chuvas em períodos que normalmente não chove, o que pode alterar estudos de vazão, por exemplo". (UM5.08)

"Sim, pois é necessário desenvolver técnicas de melhoramento de exploração de recursos naturais, considerando fatores climáticos, como índices pluviométricos, temperatura, incidência da luz solar, etc.”. (UM5.12)

Essas respostas demonstram as percepções dos alunos sobre os campos em que poderão atuar profissionalmente. De acordo com o Projeto Pedagógico do Curso - PPC (2013), o engenheiro ambiental pode atuar em diversas áreas, em ambiente urbano, rural ou industrial, listando como exemplos as seguintes atividades:

- Caracterização e planejamento ambiental do território;

- Licenciamento ambiental de atividades;

- Estudos de impacto ambiental;

- Monitoramento e avaliação da qualidade ambiental (água, solo e ar);

- Controle da poluição ambiental (água, solo 
e ar);

- $\quad$ Sistemas de gestão ambiental em atividades produtivas;

- Gerenciamento de riscos em atividades produtivas; saneamento ambiental;

- Concepção, projeto e implementação de programas e tecnologias de Ecoeficiência,

- Análise de Ciclo de Vida de Produtos e Mecanismo de Desenvolvimento Limpo (MDL) em organizações empresariais;

- Recuperação de áreas degradadas;

- Adequação e Certificação ambiental de empresas;

- Planejamento e gestão de recursos hídricos; e

- Desenvolvimento de tecnologias de proteção ao meio ambiente.

Percebe-se que, ao menos neste contexto em que os alunos buscaram relacionar a questão climática aos seus diferentes campos de atuação, estes campos não foram expressos com muita clareza, ainda que os exemplos se relacionem aos campos listados no projeto pedagógico. Gondim (2002) encontrou resultados parecidos em um estudo que buscou investigar as perspectivas de estudantes universitários quanto ao seu perfil profissional e ao mercado de trabalho. Segundo a autora, o estudante, ao ser indagado acerca de seu perfil profissional, tem dificuldade em explicitá-lo com clareza. Ao explicar a relação entre os campos citados e o tema das mudanças climáticas, os alunos também não foram precisos, não definindo em que medida esta questão se insere no campo. De modo geral, quando indicam o clima como um fator determinante para certo estudo, o apontam como uma variável que interfere no estudo.

Pode-se dizer que o principal resultado obtido através da análise das repostas que compuseram esta categoria constitui o reconhecimento, por parte dos estudantes, de que os saberes relacionados à Climatologia e, mais especificamente, à questão das mudanças climáticas, são relevantes no desenvolvimento de suas atividades. Este reconhecimento já era esperado, se consideramos o projeto pedagógico do curso, no qual: a adoção do modelo de desenvolvimento sustentado, em prol do qual o engenheiro ambiental trabalha, requer aprofundado conhecimento do meio ambiente (físico, biológico e antrópico) e de sua dinâmica, o que permite avaliar seu potencial de uso, determinar suas suscetibilidades e vocações, propor formas adequadas de apropriação dos recursos em função da capacidade de suporte do meio às atividades que nele se desenvolvem (PPC 2013, p.53). Os alunos demonstram, de fato, compreender a importância dos conhecimentos relacionados ao clima para a sua prática profissional. Considerações mais aprofundadas sobre suas concepções a respeito das mudanças climáticas, no entanto, requerem um estudo específico.

\section{Categoria B: Mitigação de impactos ambientais relacionados às mudanças climáticas}

As respostas constantes desta categoria apontaram a competência do engenheiro ambiental para mitigar impactos ambientais relacionados às mudanças climáticas. A seguir, são apresentados alguns exemplos dos argumentos utilizados.

"Sim. Um engenheiro ambiental deve buscar formas de melhorar as condições de vida do planeta, isso engloba tanto nós, seres humanos, quanto fauna e flora, e as mudanças climáticas têm relação direta com o "bem estar" do planeta". (UC5.08)

"Sim, de tal forma que podemos dar medidas mitigatórias para certos empreendimentos onde os mesmos podem diminuir suas emissões de gases poluentes e entre outras ações que interferem nas mudanças climáticas. Assim podemos diminuir essas emissões com tais atitudes para que minimize as mudanças climáticas \{sic\}". (UM5.02)

"Acredito que no futuro eu consiga diminuir um pouco, com ações de mitigação do tipo reflorestamento, reciclagem de vários materiais e dentre outros". (UM5.04)

"Sim. Atualmente não acredito que a poluição antrópica, como disse anteriormente, possa fazer diferença nas mudanças climáticas globais. Porém, se continuar aumentando, talvez daqui a alguns anos possa vir a influenciar. Por isso, como engenheiro ambiental, pretendo trabalhar para a diminuição da onsequentemente, aliviando a pressão futura que o nosso planeta possa vir a sofrer". (UM5.06)

"Sim, se realmente as mudanças climáticas tiverem origem antrópica, há práticas que podem interferir positivamente, como métodos de controle de poluição atmosférica, entre outros". (UM5.10)

Muitas destas respostas estão em conformidade com o projeto pedagógico deste curso, no que se refere à percepção dos alunos sobre possibilidades de trabalho, diferentes das respostas da categoria anterior, em que campos de atuação não foram 
muito explorados. De fato, segundo a Resolução $n^{\circ}$ 447, de 22 de setembro de 2000, que dispõe sobre o registro profissional do engenheiro ambiental e discrimina suas atividades profissionais, compete ao engenheiro ambiental o desempenho das atividades 1 a 14 e 18 descritas no artigo $1^{\circ}$ da Resolução $n^{\circ} 218$, de 29 de junho de 1973 , referentes à administração, gestão e ordenamento ambientais e ao monitoramento e mitigação de impactos ambientais, seus serviços afins e correlatos. Caracteriza-se, assim, esta modalidade da engenharia como uma área voltada à mitigação dos impactos das atividades antrópicas no meio, e os alunos cujas respostas se enquadram nesta categoria se remeteram a este aspecto.

A resposta UM5.02 citou a atuação do engenheiro ambiental no controle de emissões de gases na atmosfera. A poluição ambiental é uma matéria de formação profissional geral para a área de engenharia ambiental (Brasil 1994). Além disso, a relação estabelecida pelo aluno entre a poluição causada por atividades antrópicas e a emissão de gases concorda com as informações divulgadas pelo Painel Intergovernamental sobre Mudanças Climáticas (IPCC), por meio de seus relatórios, quanto à contribuição humana como agente modificador do clima global, o discurso dominante no âmbito da questão climática. A informação de que a distribuição do $\mathrm{CO}_{2}$ atmosférico observado aumenta com a latitude, mostrando que este aumento é impulsionado pelas emissões antropogênicas, que ocorrem principalmente nos países industrializados situados no Hemisfério Norte, divulgada pelo IPCC em 2013, exemplifica esta afirmação. Esta relação foi apontada também nas respostas UM5.06 e UM5.10, todas de alunos da disciplina de Monitoramento ambiental - cujas respostas predominaram nesta categoria. A ementa desta disciplina dá indícios de que esta predominância se deve ao fato de ela ser voltada a solução de impactos das atividades humanas em diferentes esferas, como por exemplo, nos solos e substratos, nos recursos hídricos e na atmosfera. Além da relação entre controle da poluição atmosférica e o clima, as respostas UM5.06 e UM5.10 abordaram ainda a questão da influência antrópica nas mudanças. Assim, como foi assinalado na discussão das respostas da categoria anterior, considerações sobre a percepção dos estudantes acerca de influências e causas para as mudanças climáticas requerem um estudo específico e mais detalhado, mas é interessante apontar que os alunos aludiram a esta questão. Ademais, pode-se afirmar que as respostas dos alunos se relacionam com o discurso predominante, referente à questão do clima: aquele que considera a influência antrópica no sistema climático global.

A resposta UM5.04 cita o reflorestamento e a reciclagem de materiais como medidas mitigadoras de mudanças climáticas. De fato, o desmatamento e a geração de resíduos, aliada a seu descarte incorreto, são considerados, na literatura, agravantes de mudanças climáticas. Lima (2009), por exemplo, explica como o lançamento de resíduos pode intensificar o efeito estufa, a partir da emissão de metano $\left(\mathrm{CH}_{4}\right)$, contribuindo assim para as mudanças climáticas - no caso, para o aquecimento global:

"A disposição inadequada e o não tratamento dos resíduos domésticos e industriais quando em contato com as condições climáticas (seca ou úmida) - temperatura, umidade, precipitação, ventilação - produz o chorume. (...)A decomposição de resíduos orgânicos em aterros é uma das principais fontes de emissão na atmosfera de um dos gases de maior impacto no aumento do efeito estufa - o metano $\left(\mathrm{CH}_{4}\right)$ (...)" (Lima 2009, p. 1)

O IPCC (2013) também inclui os resíduos como fonte geradora deste gás de efeito estufa:

"Existe alta confiabilidade de que o aumento de $\mathrm{CH}_{4}$ atmosférico durante a Era Industrial é causado por atividades antropogênicas. (...) As fontes antropogênicas de $\mathrm{CH}_{4}$ dominantes são o massivo aumento no número de ruminantes, as emissões provenientes do uso e extração de combustíveis fósseis, a expansão da agricultura do arroz e as emissões provenientes de aterros sanitários e resíduos”. (IPCC 2013, p. 52)

A resposta UC5.08 afirma que o engenheiro ambiental busca melhorar as condições de vida do planeta, pontuando a relação entre o clima e o "bem estar" da Terra. Ao descrever características da atuação técnica do curso, o projeto pedagógico destaca a demanda pela qualidade de vida:

"As crescentes demandas sociais por melhor qualidade de vida, emprego e renda, e o imperativo econômico e legal por melhor aproveitamento dos recursos naturais são o foco central de atuação técnica, gerencial e política do engenheiro ambiental". (PPC 2013, p.48)

Outros alunos mencionaram ainda, como medidas mitigadoras, o monitoramento das 
mudanças climáticas e o desenvolvimento de alternativas sustentáveis que minimizem os efeitos das mudanças.

Além das respostas categorizadas e das respostas dos alunos da disciplina de Ecotoxicologia, dois alunos não reconheceram relações. Dois alunos não responderam à questão. E três alunos apenas responderam afirmativamente, sem acrescentar mais argumentos à resposta.

As respostas analisadas neste trabalho são semelhantes às respostas dos sete alunos que inicialmente responderam à pergunta na primeira etapa da coleta dos dados. Todos eles reconheceram a relação entre o tema e sua futura atuação profissional, e mencionaram áreas semelhantes àquelas citadas nas respostas ora analisadas. Aqueles alunos citaram a identificação de impactos ambientais; a mitigação e adaptação aos efeitos das mudanças climáticas; o estudo do clima para a agricultura; a atuação no controle e fiscalização do desmatamento; o controle da emissão de gases de efeito estufa em indústrias; o saneamento ambiental e tratamento de água, e o estudo do clima como um dos componentes de projetos de engenharia ambiental.

De forma geral, a maioria dos respondentes considera que o tema das mudanças climáticas se relaciona à sua área na medida em que tal conhecimento deve ser considerado em seus trabalhos futuros. Estes profissionais, segundo o projeto pedagógico do curso, deverão estar preparados e deter conhecimentos compatíveis com a complexidade dos impactos decorrentes das atividades humanas no ambiente. $\mathrm{O}$ documento informa ainda que os objetivos do curso, dentre outros, são: formar profissionais com visão global, crítica e humanística, com potencial criativo de raciocínio, e capazes de avaliar a dimensão das alterações ambientais causadas pelas atividades do homem, bem como incentivar a pesquisa e a investigação científica, visando ao desenvolvimento sustentável da ciência e da tecnologia e à difusão da cultura, desenvolvendo assim o entendimento do homem e do meio como componentes integrados de um mesmo sistema. Tendo em vista estes objetivos e as habilidades que o arranjo curricular do curso busca desenvolver nos profissionais, é válido refletir sobre a contribuição dos conhecimentos geocientíficos na formação do engenheiro ambiental, uma vez que oferecem fundamentos básicos para a compreensão do mundo físico, tais como as noções de temporalidade, abrangência, ciclicidade e duração dos processos terrestres (Compiani e Gonçalves 1996). Neste sentido, destaca-se, ainda, a contribuição das geociências para o entendimento do tema das mudanças climáticas. Bacci e Martins (2013) valorizam uma abordagem contextualizada para tratar das mudanças climáticas, relacionando tempo e espaço na produção do conhecimento. Isso ajuda a compreensão do processo de fragmentação dos saberes e a criação de novas práticas e atitudes diante da realidade socioambiental, além de ser aquela que mais bem atende à proposta de formação de profissionais reflexivos e atuantes diante da sua própria realidade. As autoras complementaram que a falta de entendimento geocientífico compromete a disponibilidade e qualidade de recursos não renováveis; aumenta a insegurança habitacional e de vida; gera falsas expectativas em relação à vida no planeta e às mudanças globais, levando à incompleta compreensão do planeta e, como consequência, ao predomínio da visão reducionista e não da sustentabilidade. A visão sustentável é aquela que se espera dos engenheiros ambientais, como foi exposto ao longo deste trabalho.

\section{Conclusões}

De forma geral, os resultados obtidos apontam que os alunos investigados reconhecem de fato as relações entre a problemática atual do clima global e sua atuação profissional. A partir das análises realizadas sob a perspectiva da Análise Textual Discursiva, as respostas foram classificadas em duas linhas de argumentação. Uma delas, que abarca a maioria das opiniões dos respondentes, considera que o tema das mudanças climáticas se relaciona à atuação profissional do engenheiro ambiental porque tal conhecimento deve ser considerado em seus projetos, tais como a recuperação de áreas degradadas e a atuação na agricultura. Os argumentos, no entanto, foram pouco precisos, superficiais, ao indicar em que medida a questão se insere nestas áreas, limitando-se à constatação de que o clima influencia os campos citados. A outra indica que a questão climática está relacionada à atuação profissional do engenheiro ambiental devido à sua competência na mitigação de impactos ambientais, neste caso, de impactos relacionados às mudanças climáticas, sendo as perspectivas dos estudantes predominantemente voltadas ao controle da poluição atmosférica. 


\section{Referências Bibliográficas}

Bacci D.C., Martins V. 2013. O ensino de temas ambientais na formação de educadores em geociências e educação ambiental: mudanças climáticas no passado e presente da Terra. In: Cassiani S., Silva H.C., Pierson A.H.C. orgs. 2013. Olhares para o ENEM na Educação Científica e Tecnológica. Araraquara: Ed. Junqueira e Marin. p. 100-120.

Brasil. Decreto n. ${ }^{\circ}$ 7.390, de 9 de dezembro de 2010. Regulamenta os arts. $6^{\circ}, 11$ e 12 da Lei no 12.187 , de 29 de dezembro de 2009, que institui a Política Nacional sobre Mudança do Clima - PNMC, e dá outras providências. Diário Oficial da União, Brasília, 10 dez. 2010. URL: http://www.planalto. gov.br/ccivil_03/_Ato2007-2010/2010/Decreto/ D7390.htm. Acesso: 09.2014.

Brasil. Lei . $^{\circ}$ 12.187, de 29 de dezembro de 2009. Institui a Política Nacional sobre Mudança do Clima - PNMC e dá outras providências. Diário Oficial da União, Brasília, 30 dez. 2009. URL: http:/www. planalto.gov.br/ccivil_03/_ato2007-2010/2009/lei/ 112187.htm. Acesso: 05.2013.

Brasil. Portaria n. ${ }^{0} 1.693$, de 5 de dezembro de 1994. Cria a área de Engenharia Ambiental. URL: http://www. em.ufop.br/deamb/arquivos/PORtMEC1693_94. pdf. Acesso: 09.2014.

Brasil. Resolução n. ${ }^{\circ}$ 447, de 22 de setembro de 2000. Dispõe sobre o registro profissional do engenheiro ambiental e discrimina suas atividades profissionais. URL: http://normativos.confea.org.br/downloads/0447-00.pdf. Acesso: 09.2014.

Compiani M., Gonçalves P. W. 1996. Epistemología e Historia de la Geología como fuentes para la selección y organización del curriculum. Rev. Enseñanza de las Ciencias de la Tierra, 4(1):38-45.

Conselho Regional de Engenharia, Arquitetura e Agronomia do Rio Grande do Sul. CREA-RS. 2007. Engenheiro ambiental. Interligando desenvolvimento e meio ambiente. Conselho em Revista, 33:33.

Durkin M. 2007. A grande farsa do aquecimento global/ The Great Global Warming Swindle - vídeo 2007. URL: http://www.youtube.com/ watch?v=tpvpiBiuki4. Acesso: 05.2013.

Eerola T. T. 2003. Mudanças climáticas globais: passado, presente e futuro. In: Fórum de Ecologia, Florianópolis, 2003. (Apres. oral) URL: www.fcmc. es.gov.br/download/mudancas_climaticas_globais.pdf. Acesso: 05.2013.

Franco M.L.P.B. 2003. Análise de Conteúdo. Brasília:
Plano Ed. 72 p.

Gondim S.M.G. 2002. Perfil profissional e mercado de trabalho: relação com a formação acadêmica pela perspectiva de estudantes universitários. Rev. Estudos de Psicologia, 7(2): 299-309.

Instituto Brasileiro de Geografia e Estatística. IBGE. 2014. Sistema IBGE - Cidades@. URL: http://www.cidades.ibge.gov.br/xtras/perfil.ph $\mathrm{p}$ ? lang $=\& \operatorname{cod}$ mun $=317010 \&$ search $=$ minas -gerais| uberaba. Acesso 09.2014.

Lima D.G.G.A. 2009. A gestão dos resíduos sólidos urbanos e sua relação com as mudanças climáticas. In: Encontro Nacional, 5, e Enc. Lat.-Amer. Edif. e Comum. Sust., 3. Anais... Recife. URL: http://www.elecs2013.ufpr.br/wp-content/uploads/anais/2009/2009_artigo_005.PDF. Acesso: 09.2014.

Loureiro C. F. B. 2006. Pensamento complexo, dialética e educação ambiental. São Paulo: Cortez Ed.

Lucena A. F. P., Schaeffer R., Szklo A. 2009. A vulnerabilidade do sistema de energia elétrica à mudança climática no Brasil. In: Marengo J. A., Schaeffer R., Pinto H. S., Zee D. M.W. orgs. 2009. Mudanças climáticas e eventos extremos no Brasil. FBDS. URL: http://www.fbds.org.br/fbds/IMG/pdf/doc-504. pdf. Acesso: 06. 2013.

Marengo J.A., Tomasella J., Nobre C.A. 2011. Mudanças climáticas e recursos hídricos. In: Bicudo C.E.M., Tundisi J.G., Scheuenstuhl M.C.B. orgs. 2011. Águas do Brasil: Análises Estratégicas. Rio de Janeiro: ABC. p. 199 - 215.

Marengo J.A. 2009. Mudanças climáticas, condições meteorológicas extremas e eventos climáticos no Brasil. In: Marengo J. A., Schaeffer R., Pinto H. S., Zee D. M.W. orgs. 2009. Mudanças climáticas e eventos extremos no Brasil. FBDS. URL: http:// www.fbds.org.br/fbds/IMG/pdf/doc-504.pdf. Acesso: 06. 2013.

Martins S. R., Schlindwein S. L., D'agostini L. R., Bonatti M., Vasconcelos A.C.F., Hoffmann A. F., Fantini A.C. 2010. Mudanças climáticas e vulnerabilidade na agricultura: desafios para o desenvolvimento de estratégias de mitigação e adaptação, Rev. Bras. Ciênc. Ambientais, 17:17-27.

Melo N.P. 2012. Trabalhos de campo na semana de recepção de calouros no Instituto de Geociências/USP: institucionalização do ensino de Geociências (1972-2002), São Paulo: Fac. Educ. USP. 188 p. (Dissert. Mestrado) Ministério da Educação. e-MEC - Sistema de Regulação do Ensino Superior. 2013. URL: http://emec.mec. gov.br/. Acesso: 06.2013. 
Molion L.C.B. 2008. Aquecimento Global: uma visão crítica. In: Veiga J.E. org. 2008. Aquecimento global: frias contendas científicas. São Paulo: SENAC. p. 55-82.

Monteiro J. R. R. 1993. Plano Nacional de Saneamento PLANASA Análise de desempenho. URL: http:// www.bvsde.paho.org/bvsacg/e/fulltext/planasa/ planasa.pdf. Acesso: 06. 2013.

Moraes R. 2003. Uma tempestade de luz: a compreensão possibilitada pela Análise Textual Discursiva.. Rev. Ciência e Educação, 9(2): 191-211.

Moraes R., Galiazzi M.C. 2007. Análise Textual Discursiva. Ijuí: Ed. Unijuí. 224 p.

Ojima R., Marandola Jr. E. 2010. Indicadores e políticas públicas de adaptação às mudanças climáticas: vulnerabilidade, população e urbanização. Rev. Bras. Ciênc. Ambientais, 18:16-24.

Ometto J. P. H. B., Martinelli L. A. 2008. Ciclos biogeoquímicos. In: Buckeridge M. S. org. 2008. Biologia e mudanças climáticas no Brasil. São Carlos: Rima. p. 29 - 53.

Univ. Uberaba. 2013. Projeto Pedagógico do Curso de Graduação em Engenharia Ambiental e Sanitária Modalidade à Distância. Uberaba: Univ. Uberaba.
Rodrigues G. P. 2012. Revisão crítica das regulamentações ambientais à luz das supostas mudanças climáticas globais. São Paulo: Fac. Filos., Letr. Ciênc. Hum. USP. 318 p. (Dissert. Mestrado).

Silva D.X., Barcellos C., Bacuri R. 2010. Vulnerabilidade e efeitos das mudanças climáticas na saúde pública em Manaus. URL: http:/www.climasaude.icict. fiocruz.br/docs/vulnerabilidade_manaus_relat_ final2_x_edit.pdf. Acesso: 05.2013.

Stocker T.F., Qin D., Plattner G.K. 2013. et al. 2013. Climate Change 2013: The Physical Science Basis. Contribution of Working Group I to the Fifth Assessment Report of the Intergovernmental Panel on Climate Change [Stocker, T.F., D. Qin, G.-K. Plattner, M. Tignor, S.K. Allen, J. Boschung, A. Nauels, Y. Xia, V. Bex and P.M. Midgley (eds.)]. Cambridge: Cambridge University Press.

Suguio K. 2010. Geologia do Quaternário e Mudanças Ambientais. São Paulo: Oficina de Textos. 408p.

Universidade de Uberaba. 2013. Graduação. Engenharia Ambiental Noturno. URL: http://uniube. br/proes/det_curso.php?cd_curso $=698 \mathrm{cod}$ area $=74 \&$ tipo $=$ g. Acesso: 06. 2013. 